\title{
El derecho de la mujer trabajadora a la maternidad en Cuba: Reflexiones desde la perspectiva de la equidad de género (The right of working women to maternity in Cuba: Reflections from a gender equality perspective)
}

\author{
ONATI SOCIO-LEGAL SERIES VOLUME 11, ISSUE 3 (2021), 883-906: INVESTIGATIONS - INVESTIGACIONES \\ - IKERLANAK \\ DOI LINK: HTTPS://DOI.ORG/10.35295/OSLS.IISL/0000-0000-0000-1184 \\ RECEIVED 17 JULY 2020, ACCEPTED 11 SEPTEMBER 2020
}

\author{
JORGE LUIS SILVA GONZÁLEZ* (D) \\ SANDYS MENOYA ZAYAS* ID
}

\section{Resumen}

Los estudios relacionados con la equidad de género en el ámbito de las relaciones laborales son de trascendental importancia a escala global. En tal sentido, el presente estudio ofrece una valoración sobre la protección jurídica del derecho de la trabajadora a la maternidad en las formas de gestión de la economía cubana, teniendo en cuenta el

\footnotetext{
* Licenciado en Derecho. Máster en Desarrollo Social. Maestrante en Derecho Constitucional y Administrativo por la Facultad de Derecho de la Universidad de La Habana. Profesor Asistente del departamento de Derecho de la Universidad de Pinar del Río Hermanos Saíz Montes de Oca, Cuba. Dirección de email: jorgelsilva88@gmail.com / silva@upr.edu.cu Investiga sobre género y Derecho, y derechos humanos, líneas en la que posee varias publicaciones: a) El derecho a la maternidad de las cooperativistas en Cuba. Revista COODES. 7(2): 180-194, 2019. Cuba. b) El derecho de la mujer al trabajo y a la maternidad en Cuba. Revista Ciencias Médicas. 23(1): 147-158, 2019. Cuba. c) La protección del derecho a la maternidad de las contratadas en el sector no estatal de la economía en Cuba. Methaodos. revista de ciencias sociales. 7 (2): 274-287, 2019. España. d) Enfoque de género en el actual Código de Familia cubano. Revista Estudios del Desarrollo Social: Cuba y América Latina. 6 (1): 28-42, 2018. Cuba. e) Analizando la Masculinidad en la Ley General de la Vivienda Cubana para la Formación Profesional de Juristas. Revista GÉNEROS. Multidisciplinary Journal of Gender Studies, 7(1): 1486-1505. España. f) El enfoque de género en la evolución del ordenamiento jurídico cubano y su manifestación en el Derecho Penal actual. Revista Estudios del Desarrollo Social: Cuba y América Latina. 5 (2): 37-49, 2107. Cuba. g) El enfoque de género en el Derecho sobre bienes inmobiliarios en Cuba. Revista Santiago. ‥ 144: 492-506, 2017. Cuba. h) La formación del profesional desde el enfoque de género en el Derecho Penal cubano. Revista de Educación y Derecho. ․o 16: 1-18, 2017. España. i) El enfoque de género en las cooperativas no agropecuarias de Pinar del Río, Cuba. Revista Universidad y Sociedad. 9 (5): 111-118, 2017. Cuba. j) La Protección Jurídica de la Libertad Sexual en Cuba y España. Retos del Enfoque de Género en el Contexto de Reformas Penales. Multidisciplinary Journal of Gender Studies, 9 (2), 160-183.

${ }^{*}$ Licenciado en Economía y en Derecho. Doctor en Ciencias Económicas. Profesor Titular de Derecho del Trabajo y de Seguridad Social del Departamento de Derecho de la Universidad de Pinar del Río Hermanos Saíz Montes de Oca, Cuba. Dirección de email: sandys@upr.edu.cu Posee numerosas publicaciones asociadas a las relaciones laborales en materia de Desarrollo local, planificación, y protección del consumidor.
} 
principio constitucional de igualdad y no discriminación que debe regir para todas las mujeres con independencia de su vínculo laboral. Para ello, con el empleo de los métodos histórico-jurídico, jurídico-doctrinal y de comparación jurídica, se sistematizan los referentes doctrinales, históricos y jurídicos del derecho a la maternidad, y se analiza desde la perspectiva de la equidad su estado actual en los correspondientes regímenes especiales de seguridad social.

\section{Palabras clave}

Derecho a la maternidad; trabajo por cuenta propia; cooperativas no agropecuarias; Cuba

\section{Abstract}

Studies related to gender equality in the field of labor relations are of transcendental importance on a global scale. In this sense, this study offers an assessment of the legal protection of the worker's right to motherhood in the forms of management of the Cuban economy, taking into account the constitutional principle of equality and non-discrimination that must govern for all women. Regardless of your employment relationship. For this, with the use of the historical-legal, legal-doctrinal and legal comparison methods, the doctrinal, historical and legal references of the right to maternity are systematized, and its current status in the Corresponding special social security regimes.

\section{Key words}

Right to maternity; self-employment; non-agricultural cooperatives; Cuba 


\section{Table of contents}

1. Introducción 886

2. El derecho de la mujer trabajadora a la maternidad desde las perspectivas doctrinal, histórico-jurídica e internacional. .888

3. Estado actual de la protección jurídica de la maternidad de la trabajadora en las formas de la economía cubana

3.1. La maternidad en el sector estatal de la economía.................................................. 894

3.2. La maternidad en el sector de las cooperativas no agropecuarias...................... 895

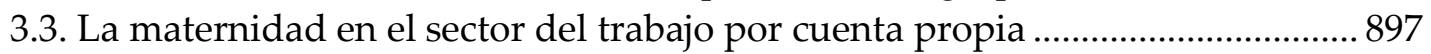
4. Análisis de la protección jurídica de la maternidad de la trabajadora desde la

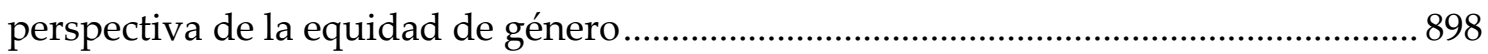

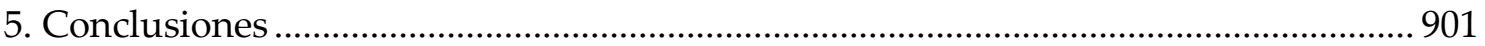

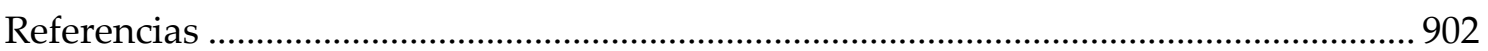

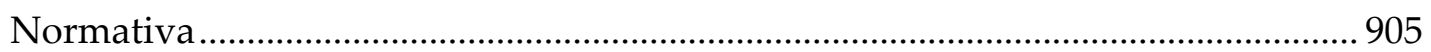




\section{Introducción}

El tratamiento del binomio trabajo-maternidad es de considerable significación a nivel internacional y deviene imperativo para organismos e instituciones, en función de contribuir a una sociedad con mayor equidad y justicia (Silva y Pérez 2017). Dicha relación constituye una discusión pertinente en un momento en el que el mundo del trabajo enfrenta grandes desafíos y existe un alcance desigual para las mujeres en relación con los hombres en materia de derechos como: acceso al empleo, condiciones laborales, salario y seguridad social.

En Cuba, desde el año 2011, con la celebración del Sexto Congreso del Partido Comunista de Cuba (PCC), en el que fueron aprobados y posteriormente implementados los Lineamientos de la Política Económica y Social del Partido y la Revolución, actualizados luego en el 2016 por el Séptimo Congreso, la mayoría de las reformas que han ocurrido están vinculadas con la economía, a propósito de la actualización del modelo económico y social cubano de desarrollo socialista (PCC 2017).

En esa dirección, el país inició también un proceso de reordenamiento laboral, en el cual la política de empleo se dirigió a diversificar las opciones de acceso para ambos sexos, a partir del relanzamiento y profundización del Trabajo por Cuenta Propia (TCP) también denominado "cuentapropismo" o "sector no estatal cuentapropista"-, y la aprobación de una nueva forma de gestión económica también ajena al sector estatal históricamente instaurado: las Cooperativas No Agropecuarias ( $\mathrm{CNoA})$, con un régimen jurídico diferente al existente para las cooperativas agrícolas.

En correspondencia con dicho proceso, y a tono con algunos cambios que ya se venían produciendo en materia legislativa en la primera década del presente siglo, se ha promulgado un grupo de normas jurídicas que marcaron la avanzada de dicho proceso, entre las cuales se encuentran:

las resoluciones 41/2013 y 33/2014, de la Ministra de Trabajo y Seguridad Social, que establecieron el Reglamento del Ejercicio del Trabajo por Cuenta Propia y el Reglamento sobre el arrendamiento de viviendas, habitaciones y espacios como actividad de trabajo por cuenta propia, respectivamente; derogadas por la Resolución 11/2018 de la referida titular y complementaria al Decreto-Ley 356/2018 del Consejo de Estado, Sobre el Ejercicio del Trabajo por Cuenta Propia;

el Decreto-Ley 278/2011 del Consejo de Estado, Del Régimen Especial de Seguridad Social para los Trabajadores por Cuenta Propia (modificado por Decreto-Ley 284/2011);

el Decreto-Ley 305/2012 del Consejo de Estado, De las Cooperativas No Agropecuarias, recientemente derogado por Decreto-Ley 366/2019 del Consejo de Estado, acompañado por su Reglamento (Decreto 356/2019 del Consejo de Ministros);

el Decreto-Ley 306/2012 del Consejo de Estado, Del Régimen especial de Seguridad Social de los socios de las Cooperativas no Agropecuarias.

Así como la actualización de otras normas tales como: la Ley 116/2013, Código de Trabajo; el Decreto-Ley 339/2016, De la Maternidad de la Trabajadora; y la vigente Constitución de la República de Cuba, ratificada mediante referendo popular el 24 de febrero de 2019 y promulgada el 10 de abril de 2019.

A partir de la implementación de dichas formas de gestión económica con una legislación propia, ha constituido una necesidad, sobre todo para los investigadores 
vinculados a dichas materias desde su rol profesional, el desarrollo de estudios sociojurídicos para su perfeccionamiento, a partir de la experiencia práctica y prestando especial atención a las políticas públicas emprendidas en pos de la equidad de género en correspondencia con los Objetivos de Desarrollo Sostenible, tema transversal en la Cuba de hoy, a todos los niveles, y en todos los proyectos emprendidos con trascendencia social.

Los saberes se han enfocado, además, hacia la garantía de los derechos de las mujeres trabajadoras en relación con los de los hombres y, particularmente, de aquellas que se encuentran en estado de gestación laborando en una CNoA o como cuentapropistas, teniendo como premisa su configuración formal en la Constitución de la República como norma jerárquica superior del ordenamiento jurídico, su ordenación y la funcionalidad del régimen jurídico especial por parte del Derecho del Trabajo y de Seguridad Social.

Específicamente, el derecho de las mujeres embarazadas que ocupan un puesto de trabajo a disfrutar del descanso prenatal y posnatal, ha sido una cuestión recurrente por el tratamiento que posee en las mencionadas formas de gestión no estatal. Por solo citar un ejemplo, en la provincia cubana de Pinar del Río, según datos estadísticos emitidos por la Dirección Provincial de Trabajo con este fin investigativo, la cifra de cuentapropistas entre mujeres y hombres ascendía en febrero de 2017 a 25 mil 334, de los cuales 8 mil 420 eran mujeres para el 33\%. Sin embargo, desde enero del año 2012 hasta diciembre de 2016 solamente 84 contratadas por otros titulares de licencia para el ejercicio del TCP han disfrutado de la licencia retribuida de maternidad (aproximadamente el 1\% del total de mujeres).

Tomando como referencia lo anteriormente expuesto se intenta en el presente estudio responder las siguientes preguntas científicas elaboradas sobre la base de la problemática detectada: ¿En qué medida se garantiza el derecho a la maternidad de la trabajadora en Cuba? ¿Existe un tratamiento equitativo para las mujeres con idéntico estatus o condición laboral en las distintas formas de economía existentes, en correspondencia con el principio constitucional de igualdad y no discriminación? En tal sentido, se persigue como objetivo valorar la protección jurídica del derecho de la mujer trabajadora a la maternidad en los sectores estatal, de TCP y de las CNoA, desde la perspectiva de la equidad de género.

Se asume en la investigación como criterio rector para el análisis de la equidad de género en los diferentes regímenes de seguridad social que protegen la maternidad, la posición y el tratamiento que ofrece a las mujeres el conjunto de normas que dan orden estructural y funcional al Derecho del Trabajo y de Seguridad Social, a partir del equilibrio que debe existir para un mismo sexo en el disfrute de los derechos, es decir, que las trabajadoras que decidan ejercitar el derecho a la maternidad accedan a las mismas prestaciones aun cuando pertenezcan a sectores de trabajo diferentes y no posean la misma condición laboral.

Las prestaciones se encuentran establecidas en el artículo ocho de la Ley 105/2008, De Seguridad Social, la cual asienta los derechos que en esta materia tienen los trabajadores, las trabajadoras y su familia a través de los regímenes de Seguridad Social (el general y los especiales). Dichas prestaciones se clasifican en: prestaciones en servicios (la asistencia médica y estomatológica, preventiva y curativa, hospitalaria general y especializada, la rehabilitación física, psíquica y laboral y otras que se determinen por la 
ley), prestaciones en especie (los medicamentos y la alimentación mientras el paciente se encuentra hospitalizado, los medicamentos que se suministran a las embarazadas, así como a los casos de accidente de trabajo y enfermedades profesionales que no requieren de hospitalización, entre otras que se determinen por la ley), y prestaciones monetarias (la pensión por edad, por enfermedad o accidente; por invalidez total o parcial; por la muerte del trabajador, pensionado o de otra persona de las protegidas por la ley; por maternidad de la trabajadora y por la asistencia social).

Para dar cumplimiento al objetivo propuesto se utilizaron en el estudio los métodos histórico-jurídico, jurídico-doctrinal y de comparación jurídica, planteados por Pérez (2011) para la solución de problemas sociales que atañen a las Ciencias Jurídicas. El método histórico-jurídico permitió el análisis sistemático e interpretativo de la evolución histórica de la protección constitucional y laboral del derecho de la mujer a la maternidad en Cuba desde su surgimiento hasta la actualidad. El método jurídico-doctrinal posibilitó el establecimiento del marco teórico conceptual de la investigación, a través del análisis de la teoría que ha sustentado la protección del derecho de las mujeres a la maternidad, en libros impresos y digitales, artículos científicos y tratados internacionales al respecto. El método de comparación jurídica facilitó la valoración del estado actual del derecho de las trabajadoras a la maternidad en el sector no estatal cuentapropista con el estatal y el no estatal cooperativo, lo cual constituirá un punto de partida para el perfeccionamiento del régimen jurídico especial establecido para los sectores analizados.

\section{El derecho de la mujer trabajadora a la maternidad desde las perspectivas doctrinal, histórico-jurídica e internacional}

"El análisis de los procesos históricos del concepto de maternidad muestra la amplitud de funciones que son comprendidas en un solo concepto: procreación, nutrición, corrección conductual, formación moral, formación afectiva, instrucción, por nombrar algunos" (Molina 2006, p. 94). Se identifica con la imagen de mujer, las nociones de crianza y la influencia de no solo factores culturales, sino también sociales, como vertientes que se encuentran y entrecruzan en la interpretación (Molina 2006). Teóricamente, su definición es amplia teniendo en cuenta la multiplicidad de criterios que ha generado y las clasificaciones que se le asignan.

Al estudiar la maternidad como construcción simbólica, es necesario partir de la base de que ésta ha sido cimentada como una categoría discursiva que refleja dinámicas de dominación/subordinación, develando el funcionamiento social y simbólico que el patriarcado impone mediante discursos normativos, los cuales establecen una simbiosis entre identidad femenina y maternidad que sitúa la capacidad reproductora de la mujer como parte de su deber ser. (Contreras 2018, p. 211)

Según Moncó (2009) es una categoría ontológica que fundamenta la subjetividad femenina, legitima la desigualdad de género y una relación de dominación entre el hombre y la mujer, apuntando hacia la naturaleza biológica que es, en sí misma, una construcción social naturalizada. En tal sentido, para Imaz (2010) y Ramírez-Ramírez (2013) constituye además de un proceso biológico, una experiencia, un rol, un estatus, una práctica cotidiana, una posición social y un elemento identitario que posee otra sociocultura. 
Considera Walker (1995) que algunos estudios de la temática han indicado la necesidad de distinguir la maternidad como práctica (que envuelve la relación entre madre e hijo, así como la relación entre la madre y el resto del conjunto social), la maternidad como discurso (conjunto de normas, valores e ideales en torno al ser madre) y la maternidad como identidad social (membrecía a un grupo y reconocimiento).

Existen varias nociones para determinar la maternidad (Duarte 2004). Se habla hoy de concepción genética, gestacional, afectiva, procreacional o volitiva, biológica, jurídica (Figueroa 1995), y más allá de su determinación, o a tono con ello, se debate también sobre el tratamiento que en cada caso le corresponde a la mujer jurídicamente, es decir, en el ejercicio del derecho a la maternidad siendo o no trabajadora.

La maternidad envuelve una contradicción importante: puede actuar como un elemento de coacción, al mismo tiempo que provee un camino para la realización personal de algunas mujeres (Arendell 2000). La experiencia genera satisfacciones y paralelamente desencadena conflictos, por lo que podría afirmarse que la maternidad implica negociaciones constantes en la construcción de la subjetividad femenina (Imaz 2010).

Para Mander y coautoras (2014), la maternidad se encuentra siempre en una intersección de variables histórico-culturales, pues en la actualidad la percepción que se tiene de la maternidad depende de cuestiones como la autonomía que la sociedad le concede a las mujeres, el poder político o los valores culturales asociados a la raza, la clase y la orientación sexual.

También pudiera afirmarse que la maternidad constituye la relación que une a la madre con el hijo. Llámense "maternidades" a los establecimientos públicos o privados en que se presta asistencia a las mujeres parturientas. En tanto, "mujer encinta" se refiere a la embarazada que goza de cierta protección jurídica. Si es trabajadora, tiene derecho a un descanso de varias semanas previo al parto, con percepción íntegra del sueldo (Ossorio 2004, 602).

En el ámbito de las Ciencias Jurídicas, no se puede dejar de mencionar que el binomio mujer-Derecho asociado a las cuestiones de género, es centro de atención para la teoría jurídica feminista, la cual comprende enfoques sobre la discriminación de las mujeres y el Derecho. En ese sentido, según González (2015, p. 25), en el tercer enfoque, "que recoge el impacto del posestructuralismo y de la filosofía posmoderna en el feminismo, lo que se nos dice es que el Derecho es ante todo discurso", un lenguaje generativo, constituyente, "que elige actuar, regulando, nombrando determinados hechos, temas, individuos" (Ibid.). Como expresara Smart (citado en González 2015, p. 25) el género actúa sobre el Derecho, y el Derecho, a su vez, produce género. Ello se pudiera materializar en el poder que tiene el Derecho a través de normas jurídicas para contribuir a la eliminación de brechas de inequidad o reproducir patrones de discriminación entre los sexos masculino y femenino, o dentro de un mismo sexo.

La maternidad tiene la naturaleza de un hecho jurídico relacionado con la reproducción del ser humano, del cual surgen derechos y obligaciones (Kurczyn 2004); implica una proyección de la dignidad humana y el libre desarrollo de la personalidad, que rebasa las fronteras del ejercicio de la libertad reproductiva (Marrades 2002, p. 28); representa el origen de diversos derechos dentro de un sistema de seguridad social (Gamboa y Valdés 2008), cuyo tratamiento legal adquiere una gran importancia dentro del marco 
del Estado Social de Derecho, ya que se convierte en una necesidad social que interesa tanto a mujeres como a hombres en las relaciones laborales (Berrocal y Reales 2016).

Desde el punto de vista doctrinal, en Cuba, la literatura aborda con frecuencia el tema de la maternidad desde los componentes biológico y sociocultural, sin embargo, pudiera afirmarse que existe un escaso tratamiento del término como derecho y específicamente desde las ramas del Derecho Constitucional (como derecho fundamental) y del Derecho del Trabajo y de Seguridad Social, sobre todo en la producción científica al efecto. Las nociones más cercanas provienen del proceso de creación de tratados internacionales por parte de la Organización de Naciones Unidas (ONU), a la que corresponde la iniciativa legislativa en materia de derechos humanos, pero sin ofrecer tampoco una definición propia o extensiva para la Comunidad Internacional en la materialización de dicho derecho.

Ante tal situación, se entenderá en la presente investigación el derecho a la maternidad de la trabajadora, como el derecho que le asiste a la embarazada que ocupa un puesto de trabajo de recibir a través del Sistema de Seguridad Social prestaciones en servicios, en especies y monetarias para asegurar su estatus, desde la concepción hasta los meses iniciales de alumbramiento, de manera tal que se preserven su salud y la del recién nacido, y que resulte habilitada para combinar satisfactoriamente sus roles reproductivo y productivo una vez reincorporada a su plaza habitual, a la vez que se preserven las garantías para el ejercicio del resto de sus derechos laborales.

A dicho criterio se suma que, según la Organización Internacional del Trabajo (OIT), la protección de la maternidad es un derecho laboral fundamental y ha quedado consagrado en tratados universales fundamentales de derechos humanos (Addati et al. 2014). La ONU, como sujeto de Derecho Internacional Público y principal estructura internacional que aglutina en su seno a 193 Estados, ha desarrollado disímiles acciones en defensa de los derechos de la mujer y específicamente el relacionado con la maternidad de las trabajadoras, correspondiéndole incluso la iniciativa normativa al respecto, al considerarse como un derecho humano a respetar y garantizar su efectividad por la Comunidad Internacional.

Desde su creación en el año 1945, a través de la Carta constitutiva de la Organización, las naciones reafirmaron su voluntad de contribuir a la protección de los derechos fundamentales del hombre, constituyendo precisamente uno de los propósitos esenciales de dicha asociación. Tanto es así que tres años después, en 1948, se creó el tratado "madre" en materia de derechos humanos: la Declaración Universal de los Derechos Humanos (DUDH), adoptada por la Asamblea General de Naciones Unidas (AGNU) en Francia.

En relación con el derecho a la maternidad de las trabajadoras en el artículo 25 en sus dos apartados plantea:

1. Toda persona tiene derecho a un nivel de vida adecuado que le asegure, así como a su familia, la salud y el bienestar, (...), tiene asimismo derecho a los seguros en caso de desempleo, enfermedad, invalidez, viudez, vejez u otros casos de pérdida de sus medios de subsistencia por circunstancias independientes de su voluntad. 
2. La maternidad y la infancia tienen derecho a cuidados y asistencia especiales. Todos los niños, nacidos de matrimonio o fuera de matrimonio, tienen derecho a igual protección social.

A tono con la DUDH, se adoptó por la AGNU en el año 1966 y entró en vigor el 3 de enero de 1976 el Pacto Internacional de los Derechos Económicos Sociales y Cultuales (PIDESC), el cual establece en el artículo nueve que: “Los Estados Partes en el presente Pacto reconocen el derecho de toda persona a la seguridad social, incluso al seguro social". Asimismo, en el artículo 10 se plantea que los Estados reconocen que "(...) se debe conceder especial protección a las madres durante un período de tiempo razonable antes y después del parto. - Durante dicho período, a las madres que trabajen se les debe conceder licencia con remuneración o con prestaciones adecuadas de seguridad social".

Previo a la adopción de la DUDH, el Consejo Económico y Social de la ONU había creado en 1946 la Comisión de la Condición Jurídica y Social de la Mujer con el objetivo de presentarle informes sobre la promoción de los derechos de las féminas en los ámbitos político, económico, civil, social y educativo, así como formular recomendaciones y propuestas de acción sobre problemas urgentes que las afectan.

En correspondencia con lo planteado por la DUDH y el PIDESC, la ONU fundó el Comité para la Eliminación de la Discriminación contra la Mujer, con el objetivo de supervisar la aplicación de la Convención sobre la eliminación de todas las formas de discriminación contra la mujer (CEDAW, por sus siglas en inglés), la cual fue aprobada por la AGNU en diciembre de 1979. Dicho órgano tiene la potestad de hacer recomendaciones que promuevan el respeto a los derechos humanos y su efectividad, y otorgar exclusiva observancia al desenvolvimiento económico-laboral y social de las mujeres.

El Estado cubano no ha estado ajeno a la política jurídico-social establecida como parte de la Comunidad Internacional; es signatario de la DUDH, firmó el PIDESC y, aunque no lo ratificó, se define constitucionalmente como un Estado socialista de derecho y justicia social, democrático, independiente y soberano, organizado con todos y para el bien de todos como república unitaria e indivisible, fundada en el trabajo, la dignidad, el humanismo y la ética de sus ciudadanos para el disfrute de la libertad, la equidad, la igualdad, la solidaridad, el bienestar y la prosperidad individual y colectiva. El valor concedido al trabajo en esta sociedad tiene como premisa la tradición del movimiento obrero, cuyas intensas jornadas de lucha condujeron al logro de sus mayores conquistas.

Dentro de los derechos de la clase obrera, la mujer ha sido centro de atención en varias normas jurídicas, sobre todo a partir del triunfo de la Revolución cubana el primero de enero de 1959, año en el que se aprobó la Ley Fundamental de 1959. Esta norma, en lo concerniente a la maternidad, enfatizaba en la responsabilidad del Estado en su protección y establecía que la ley regulará la protección de la maternidad obrera, extendiéndola a las empleadas, manifestando además que la mujer grávida no podrá ser separada de su empleo, ni se le exigirá efectuar, dentro de los tres meses anteriores al alumbramiento, trabajos que requieran esfuerzos físicos considerables. Durante las seis semanas que precedan inmediatamente al parto y las seis semanas que le siguen gozará de descanso forzoso, retribuido igual que su trabajo, conservando el empleo y todos los derechos anexos al mismo y correspondientes a su contrato de trabajo. En el período de 
lactancia se le concederán dos descansos extraordinarios al día, de media hora cada uno, para alimentar a su hijo (Ley Fundamental, 1959).

Posteriormente, se dictó la Ley 1100 de 1963, la cual propició el perfeccionamiento del Sistema de Seguridad Social cubano. En relación con el Seguro Social de Maternidad se plasmaron y ampliaron los principios encaminados a proteger a la mujer tanto en el sector estatal como en el privado.

A raíz de las transformaciones realizadas en Cuba a favor de la maternidad y los niños, se aprobó 11 años después, la Ley 1263 de 1974, Ley de la Maternidad de la Mujer Trabajadora, que protegía en el orden médico laboral a la mujer y su descendencia, así como la responsabilidad de la entidad laboral para que ello se cumpliera. Disponía de la atención médica periódica durante el embarazo, concediéndosele licencia retribuida desde las seis semanas anteriores al parto hasta las doce posteriores. En el caso de embarazo múltiple, la licencia retribuida anterior al parto se extendía a ocho semanas y el receso era desde las treinta y dos semanas. Tenían derecho también a licencias retribuidas complementarias para facilitar la atención médica de su hijo y se autorizaba a la madre a que un día al mes concurriera a la consulta de puericultura con su hijo sin pérdida de salario.

Heredera de los principios revolucionarios de la Ley Fundamental de 1959, se aprobó una nueva Constitución de la República de Cuba en 1976, la cual reconoció que "[e]l Estado protege la familia, la maternidad y el matrimonio", y en tal sentido, garantiza la seguridad social por causa de la maternidad, pues en su artículo 44 referido a la igualdad se planteaba que "al velar por su salud y por una sana descendencia, el Estado concede a la mujer trabajadora licencia retribuida por maternidad, antes y después del parto, y opciones laborales temporales compatibles con su función materna".

En cuanto a la regulación del acceso de la mujer al trabajo en Cuba, el anterior Código de Trabajo (Ley 49/1984), destinaba el capítulo octavo a regular el trabajo de la mujer. Establecía que las administraciones de las entidades laborales no emplearían a mujeres en estado de gestación o con disposición para tener descendencia en labores que pudieran afectar el embarazo y/o afectar su aparato ginecológico y función reproductora. Para ello, debía existir en los centros de trabajo una lista de puestos en los que no se podía ubicar a la mujer, la que se confeccionaba centralizadamente tomando como referencia los Tratados Internacionales suscritos por Cuba.

Por último, el capítulo destinado a la protección de la mujer establecía las licencias a las que tenía derecho la trabajadora en estado de gestación o con hijos menores de un añola retribuida de maternidad y otras complementarias, por ejemplo, para la lactancia materna- y la exención de realizar trabajo extraordinario en su modalidad de horas extras o dobles turnos, o comisión de servicio fuera de la localidad. Dicho cuerpo normativo, fundamentado en el principio de reserva de ley, encomendaba a la norma especial la regulación de los procedimientos necesarios para el disfrute efectivos de estos derechos, a la que se hará referencia en el epígrafe destinado a la normativa de la maternidad.

A principios del siglo XXI, se implementó el Decreto-Ley 234 de 13 de agosto de 2003, De la Maternidad de la Trabajadora (modificado mediante el Decreto-Ley 285/2011 y derogados ambos posteriormente por el Decreto-Ley 339/2016 del Consejo de Estado), el 
cual adecuaba las disposiciones de la Ley 1263 de 1974. En la exposición de motivos se evidencia que el objetivo principal era fortalecer las relaciones familiares, toda vez que es la familia la célula principal de la sociedad. Pretendía implicar en el cuidado y la educación de los menores no solo a la madre y al padre, sino al resto de los parientes que efectivamente contribuyeran al cuidado de niñas y niños, teniendo en cuenta la responsabilidad de ambos padres con los menores, establecida en el Código de Familia, y la ampliación de los derechos y beneficios para la trabajadora.

Al igual que la Ley 1263/1974, el Decreto-Ley 234/2003 regulaba los descansos y suspensiones de la relación laboral en idéntico grado y sentido, sin embargo, extendía la protección a la trabajadora contratada por tiempo determinado en una entidad estatal. Si arribaba a las 34 o 32 semanas de embarazo antes de terminar el contrato de trabajo, tenía derecho al disfrute de la licencia de maternidad. El derecho a la retribución de dicha licencia con el cobro de la prestación económica estaba condicionado al cumplimiento de requisitos adicionales, los que se analizarán más adelante.

Téngase en cuenta que en el año 2003 no se había flexibilizado aún el ejercicio del TCP; no se autorizaba la contratación de fuerza de trabajo por personas naturales, por tanto, el vínculo laboral se limitaba a los empleadores estatales. Existían un sector agropecuario privado y cooperativo y un sector de la inversión extranjera a los que se les garantizaba también la protección referida, aunque en proporción al sector empresarial estatal estos no eran significativos.

El Decreto Ley 234/2003 también regulaba los derechos del padre, abuelos o hermanos paternos o maternos de acceder a la prestación social y demás licencias complementarias a las que tendría derecho la madre, si esta falleciera mientras disfruta de la licencia postnatal, siempre que se cumplieran los requisitos establecidos.

Diez años más tarde se aprobó el vigente Código de Trabajo (Ley 116/2013), el cual, de manera general, no difiere en la protección de la trabajadora en relación con la Ley 49/1984, sino solo agrega en su reglamento los períodos computables a la trabajadora para determinar el cumplimiento de los setenta y cinco días de trabajo necesarios para concederle la prestación económica de la licencia retribuida de maternidad.

El ánimo de las normativas anteriores tendentes a reconocer el derecho a la maternidad de la trabajadora por medio de la seguridad social se materializa en la Constitución de la República de Cuba de 2019, la cual en el artículo 68 establece que: "La persona que trabaja tiene derecho a la seguridad social. El Estado, mediante el Sistema de Seguridad Social, le garantiza la protección adecuada cuando se encuentre impedida de laborar por su edad, maternidad, paternidad, invalidez o enfermedad"; y más adelante en el Capítulo de Las Familias, precepto número 84, recalca que "la maternidad y la paternidad son protegidas por el Estado". 


\section{Estado actual de la protección jurídica de la maternidad de la trabajadora en las formas de la economía cubana}

\subsection{La maternidad en el sector estatal de la economía}

En consonancia con la Constitución cubana de 1976 y la recientemente promulgada Constitución de la República de 2019, la Ley 105/2008, De Seguridad Social, reconoce en el artículo 11 inciso e) a las prestaciones por maternidad de la trabajadora como una de las formas de las prestaciones monetarias, y a su vez regula en la primera de las disposiciones especiales que los derechos laborales y de seguridad social de la mujer trabajadora para proteger su maternidad, que facilitan su atención médica durante el embarazo, el descanso pre y postnatal, la lactancia materna y el cuidado de los hijos menores de edad, se rigen por la legislación específica para todos los sectores de la economía, lo que lógicamente quiere decir que no solo el sector estatal, sino el de las CNoA y el de TCP también tendrán su propio régimen.

En el 2017 entró en vigor en Cuba una nueva disposición que regula la maternidad de la trabajadora estatal: el Decreto-Ley 339 de fecha 8 de diciembre de 2016. El principal objetivo del mismo es la estimulación de la fecundidad, incorporación y reincorporación de la mujer al trabajo. En relación con los derechos de la trabajadora para el disfrute de la licencia de maternidad mantiene lo establecido por el Decreto-Ley 234/2003, así como los derechos de la madre ante el fallecimiento de su hijo o hija menor, y los del padre y familiares del menor en caso de fallecimiento de la madre.

Como aspecto significativo para el logro del objetivo de la norma, se orienta que la trabajadora sin vínculo laboral, que haya sido contratada por tiempo determinado en períodos superiores a un año, cuyo último contrato haya terminado en un período no mayor de tres meses con anterioridad al cumplimiento de las 34 o las 32 semanas de embarazo, tiene derecho al disfrute de las licencias pre y postnatales. El pago de la prestación económica se efectúa por la filial municipal del Instituto Nacional de Seguridad Social o la Dirección Municipal de Trabajo de la localidad de la trabajadora, y esta tiene que haber laborado al menos 75 días en el período anterior al comienzo del disfrute de la licencia prenatal. De no ser así, tiene derecho a la licencia de maternidad, pero sin retribución.

Este Decreto-Ley 339/2016 dispone mayores beneficios económicos para la trabajadora. En el artículo 5 plantea que la trabajadora que por prescripción médica no pueda seguir vinculada a su puesto de trabajo, tiene derecho a que se le traslade de trabajo con el $100 \%$ del promedio de salarios recibidos en los 12 meses anteriores. De no poder reubicarse, tiene derecho entonces al pago del $60 \%$ de ese promedio de salarios, todo lo cual tiene lugar antes del inicio de la licencia prenatal.

En cuanto al pago de la licencia, este cuerpo legal reconoce que la trabajadora con más de una relación laboral tendrá derecho a percibir prestaciones económicas por cada uno de los contratos de trabajo, siempre que cumpla los requisitos de tiempo establecidos. Sin embargo, para el cálculo de la licencia hace alusión a los 12 meses anteriores y a las 52 semanas, pero no alude a ingresos semanales, sino a salario promedio.

En relación con lo anterior, el artículo 126 del Decreto 326/2014, Reglamento del Código de Trabajo, establece en su inciso c) que el salario promedio es el resultante de dividir los 
salarios de seis meses anteriores entre el tiempo trabajado. Se puede apreciar que la Ley establece un cálculo de salario promedio más ventajoso para la madre trabajadora que para una trabajadora o trabajador fuera de esta categoría, lo cual se considera completamente acertado.

El vigente Decreto-Ley 339/2016 regula que, si el parto tiene lugar antes de finalizar la licencia prenatal, y la trabajadora había recibido al pago completo correspondiente a la misma, se debía deducir dicha cuantía del pago de la licencia postnatal. Dispone además que la madre que se incorpora al trabajo antes del año de vida del menor puede simultanear el cobro del salario correspondiente a la plaza que ocupa con el cobro de la prestación social, que en ambas normas legales asciende al 60\% de la base de cálculo de la licencia retribuida de maternidad.

Por último, y no menos importante, es la protección que brinda a las trabajadoras disponibles (pendientes de reubicación laboral) por habérseles amortizado su plaza o porque su entidad se extinguió y no se subrogó otra en su lugar. Estas trabajadoras si se encuentran reubicadas temporalmente o con garantía salarial y cumplen los requisitos establecidos, tienen derecho a la prestación económica si en ese término arriban a la fecha en que les corresponde la licencia de maternidad. Asimismo, aquella que se encuentre disponible y logre demostrar que en el momento de causar baja se encontraba en estado de gestación, también tiene derecho al cobro de la prestación social.

En este sector de la economía, la trabajadora tiene acceso a todas las prestaciones establecidas por la Ley de Seguridad Social cubana: en servicios, en especie y monetarias.

\subsection{La maternidad en el sector de las cooperativas no agropecuarias}

Es preciso enfatizar que aun cuando en la Ley Marco para las Cooperativas de América Latina (Alianza Cooperativa Internacional para las Américas, 2009) no se regula el derecho a la maternidad, en armonía con la política de seguridad social cubana, el Decreto-Ley 306/2012, del Régimen especial de Seguridad Social de los socios de las Cooperativas No Agropecuarias (CNoA), sí lo reconoce en el artículo 2 al plantear:

Artículo 2: El régimen especial de seguridad social que por este Decreto-Ley se establece protege a los cooperativistas en los casos de enfermedad y accidente de origen común o profesional, maternidad, invalidez total, vejez, y en caso de muerte, protege a su familia.

También el artículo 23 establece las condiciones por las que se exime del pago de la contribución a la seguridad social, incluyendo la maternidad, y el 26 se pronuncia al respecto:

Artículo 23: Al cooperativista se le exime del pago de la contribución a la seguridad social y se mantiene afiliado al régimen, si concurren las causas siguientes:

(a) La maternidad de la cooperativista durante el período en que se encuentra disfrutando de la prestación económica y social (...).

Artículo 26: A los efectos de conceder el derecho a la licencia retribuida por maternidad y a las pensiones establecidas en el presente Decreto-Ley, se equiparan como tiempo de contribución los siguientes:

(a) El período en que la cooperativista disfruta de las prestaciones por maternidad (...). 
A pesar de lo establecido, cabe resaltar que el artículo 32 de dicho Decreto-Ley remite a la cooperativista a la legislación de la trabajadora asalariada respecto a la protección del derecho a la maternidad, no obstante ser sujetos de regímenes diferentes, quedando esta legislación sin regular contenido propio a este derecho (artículo 32: "El derecho a la protección de la maternidad de la cooperativista se rige por la legislación que regula la protección a la maternidad de la trabajadora asalariada").

Por otra parte, el artículo 33 se refiere a las prestaciones por maternidad que se garantizan a la cooperativista teniendo en cuenta el período de trabajo en la $\mathrm{CNoA}$ :

Artículo 33: Para realizar el cálculo de las prestaciones por maternidad a que tenga derecho la cooperativista, se considera la base de contribución por la que aportó al presupuesto de la seguridad social en los doce meses anteriores al inicio del disfrute de la prestación. Si dentro de este período la cooperativista tuvo la condición de asalariada, se incluyen en la base de cálculo los salarios percibidos.

Si la cooperativista tiene menos de doce meses de incorporada al trabajo, la prestación monetaria se calcula sobre el ingreso base por el que se encuentra contribuyendo en la fecha que le corresponde recibir la prestación.

El capítulo VIII está dedicado al Procedimiento para el trámite por los subsidios, las prestaciones por maternidad y las pensiones. A su interior, el artículo 48 reconoce que es el Órgano de Administración de la Cooperativa el que tiene a su cargo la gestión administrativa de ese régimen especial de seguridad social, e incluye entre sus apartados el siguiente:

f) solicitar a la filial municipal del Instituto Nacional de Seguridad Social que expida las órdenes de pago de la prestación económica y social en los casos de licencia por maternidad (...).

En relación con ello, el artículo 49 plantea que el Director de la Filial Municipal del Instituto Nacional de Seguridad Social, además de las funciones establecidas en la legislación correspondiente, tiene la de expedir las órdenes de pago de la prestación económica y social en los casos de licencia por maternidad.

Al analizar el Modelo de Estatutos del Ministerio de Justicia, lo que hace este es remitir al Decreto Ley 306, al establecer que:

El Órgano de administración de la cooperativa precisará con cada socio el Régimen Especial de Seguridad Social a que se afiliará en correspondencia con la escala que establece el Decreto Ley 306, De la Seguridad Social de las cooperativas no agropecuarias, al efecto de las retenciones que realizará para el aporte de las obligaciones tributarias.

En igual caso se encuentra la Guía de Estatutos al considerar en su Sección VI: De la Seguridad Social, artículo 53 que:

El Órgano de administración de la cooperativa precisará con cada socio el Régimen Especial de Seguridad Social a que se afiliará en correspondencia con la escala que establece el Decreto Ley 306, De la Seguridad Social de las cooperativas no agropecuarias, al efecto de las retenciones que realizará para el aporte de las obligaciones tributarias.

En este sector de la economía, aunque sin una regulación propia y acabada del derecho a la maternidad que reenvía al régimen estatal, la trabajadora contratada también tiene acceso a todas las prestaciones establecidas por la Ley de Seguridad Social cubana: en servicios, en especie y monetarias. 


\subsection{La maternidad en el sector del trabajo por cuenta propia}

La ampliación del trabajo por cuenta propia y la autorización de nuevas figuras en dicho sector ha sido considerado por Dujarric y Vázquez (2015) como una de las medidas de impacto bien acogidas entre la población y con un alcance individual, familiar y social. Para Rodríguez (2014) está conformado en principio por elementos subjetivos que existen en todo el mundo, pero con una denominación diferente en el panorama cubano:

El empleador de fuerza de trabajo o lo que es lo mismo el trabajador privado de la economía, es denominado por la legislación cubana como Titular de la licencia para ejercer el trabajo por cuenta propia y el trabajador subordinado a este se denomina Trabajador contratado. Todo ello encuentra su génesis en una legislación que amén de autorizar el trabajo por cuenta propia o no estatal no ha actualizado su legislación laboral atemperándola a los nuevos actores del Derecho Laboral cubano; empleadores privados y trabajadores no estatales. (Rodríguez 2014, 106)

Para Odriozola y Colina (2018, p. 8) "el esquema diseñado para la seguridad social en el cuentapropismo recoge un tratamiento diferenciado al sexo femenino", y la posibilidad de las mujeres contratadas de beneficiarse con la licencia de maternidad constituye una de sus principales fortalezas (Echeverría y Lara 2012).

Dicho esquema está en consonancia con la vigente Ley 116, Código de Trabajo, que regula en su artículo dos los principios fundamentales que rigen el derecho de trabajo, al plantear de forma general que el trabajo es un derecho y un deber social del ciudadano; que todo ciudadano en condiciones de trabajar tiene derecho a obtener un empleo atendiendo a las exigencias de la economía y a su elección, tanto en el sector estatal como el no estatal -sin discriminación-, así como los derechos de trabajo y de seguridad social que se confieren a la trabajadora para proteger su maternidad y facilitar su atención médica, el descanso pre y postnatal y el cuidado de los hijos menores. En tal sentido, se reconocen estos y otros derechos en el capítulo cuarto que dedica cinco artículos, del cincuenta y nueve al sesenta y dos, a establecer la protección de la trabajadora.

Es preciso plantear que la actual Constitución de la República de 2019 reafirma el reconocimiento del derecho a la seguridad social; plantea que el Estado, mediante el Sistema de Seguridad Social, garantiza la protección adecuada de todo trabajador impedido de laborar por su edad, maternidad, paternidad, invalidez o enfermedad.

Debe tenerse en cuenta que el objeto de regulación del Derecho del Trabajo lo constituyen las relaciones de trabajo donde exista ajenidad y subordinación, y como ambas madres -las del sector estatal y las del no estatal cuentapropista- se subordinan a sus empleadores, ya sean en empresas estatales en el primer caso o a personas naturales titulares de licencia en el segundo, se consideran trabajadoras asalariadas con idénticas necesidades.

Particularmente, la subordinación a un empleador privado o persona natural con capacidad legal para contratar a uno o más trabajadores, se establece en el Código de Trabajo, en el artículo 9 inciso b). En tal sentido, para Rodríguez y Páez, “(...) la relación laboral entre personas naturales está signada por la plena autonomía de la voluntad de las partes, amén de que el empleador se encuentra compelido al cumplimiento de los deberes y obligaciones de la legislación laboral (...)" (Rodríguez y Páez 2016, p. 12). 
Específicamente, la protección de la maternidad en este sector se regula por el DecretoLey 278 de 2011, en el cual se plantea, grosso modo, que:

Artículo 26: La trabajadora gestante tiene derecho a una licencia retribuida por maternidad al cumplir las treinta y cuatro semanas de embarazo, por el término de dieciocho semanas que comprende las seis anteriores al parto y las doce posteriores.

Artículo 27: Para tener derecho al cobro de la licencia retribuida por maternidad regulada en el artículo anterior, es requisito indispensable que la gestante haya contribuido al régimen, como mínimo, durante los doce meses inmediatos anteriores a la fecha de inicio de la licencia.

Asimismo, se refiere en los artículos que le suceden, del 28 al 32, respectivamente, a los casos en que se produzca el parto antes de las treinta y cuatro semanas; al fallecimiento del hijo en el momento del parto, y a la cuantía de la prestación monetaria en relación con el tiempo de trabajo.

\section{Análisis de la protección jurídica de la maternidad de la trabajadora desde la perspectiva de la equidad de género}

Para valorar la protección jurídica de la maternidad de la trabajadora en las formas de gestión de la economía cubana en estudio aquí y desde la perspectiva de la equidad de género, es necesario referirse a algunos criterios jurídico-doctrinales en torno a la equidad que sustentaron el análisis desarrollado.

Desde el punto de vista del Derecho, la perspectiva de género "establece una teoría social que trata de explicar (...) comportamientos sociales de hombres y mujeres en sociedad, (...) destacando la existencia real del género femenino y masculino, sin dominio de uno sobre el otro, sin jerarquías y sin desigualdades" (Camargo 1999, p. 29).

A criterio de Miranda y Peña, equidad de género es la distribución justa de acuerdo con los intereses y necesidades de hombres y mujeres; es tener derecho a acceder con justicia e igualdad al uso, control y beneficio de los mismos bienes y servicios de la sociedad, así como a la toma de decisiones en los ámbitos de la vida social, económica, política, cultural y familiar. "Es la aceptación de las diferencias entre hombres y mujeres, y la aceptación también de derechos, buscando el ideal de un equilibrio en el que ninguno de ambos sexos se beneficie de manera injusta en prejuicio del otro" (Miranda y Peña 2001, p. 77).

Según Valdebenito (2002, pp. 37 y 44) supone un disfrute de los bienes sociales, recursos, las mismas oportunidades en la toma de decisiones, y trabajar juntos ambos sexos para lograrlo. Coinciden Miranda y Peña (2001) y Valdebenito (2002) en que la equidad de género no supone que hombres y mujeres sean iguales, pero sí que tengan acceso y disfruten de los bienes sociales, oportunidades y recursos sin distinción alguna, sin que un sexo prevalezca por encima del otro.

Para Trujillo y Hernández (2008, p. 462), “equidad es un término que expresa equilibrio, igualdad en las oportunidades, una relación justa", mientras que Maurizio (2010, p. 8) considera que "la equidad de género es un elemento esencial para alcanzar niveles elevados de desarrollo económico, integración social y para construir sociedades democráticas donde la ciudadanía sea ejercida plenamente". 
En tal sentido, se asume en la investigación como criterio rector para el estudio de la equidad de género en los diferentes regímenes de seguridad social que protegen la maternidad, no solo la posición y el tratamiento que ofrece para hombres y mujeres el conjunto de normas que dan orden estructural y funcional al Derecho del Trabajo, sino también al equilibrio que debe existir para un mismo sexo en el disfrute de los derechos, es decir, que las trabajadoras que decidan ejercitar el derecho a la maternidad posean las mismas prestaciones aun cuando pertenecen a sectores de trabajo diferentes.

Atendiendo a lo expuesto hasta ahora, se aprecia un enfoque discriminatorio para la mujer trabajadora en estado de gestación del sector de TCP, en relación con la del sector estatal, toda vez que no existe coherencia normativa en el tratamiento estipulado por el régimen especial de seguridad social correspondiente.

Si bien es cierto que en los referidos sectores disfrutan las gestantes de la prestación económica durante dieciocho semanas: seis prenatales y doce posnatales, la mayor distinción radica en que a la trabajadora del sector estatal a través del Decreto-Ley $339 / 2016$, se le garantizan derechos conexos que no encuentran reconocimiento en el Decreto-Ley 278/2011 para las cuentapropistas, a saber:

- La garantía de reincorporación a su plaza de trabajo.

- A percibir la prestación social que se otorga a la madre, padre o familiar a quien se encargue el cuidado del menor al vencimiento de la licencia postnatal y hasta que este arribe a su primer año de vida.

- A la simultaneidad del cobro de la prestación social con el salario, cuya cuantía asciende al $60 \%$ de la base de cálculo de la licencia retribuida por maternidad.

- La disposición de tiempo para la atención estomatológica.

- A la suspensión de la relación laboral con carácter obligatorio para garantizar su descanso ante la proximidad del parto, así como para su recuperación posterior al nacimiento del menor.

Además, dicha trabajadora debe contribuir al régimen especial de seguridad social al menos los doce meses anteriores al comienzo del disfrute de la licencia de maternidad para tener derecho al cobro de la prestación económica, a diferencia de la trabajadora estatal que solo debe demostrar setenta y cinco días laborados dentro del año anterior a la fecha en cuestión. Tampoco se dispone el derecho de la trabajadora del sector no estatal cuentapropista a las licencias complementarias para la lactancia del menor.

También es criterio nuestro que la tipología de contrato de trabajo que estipula la ley laboral vigente para las relaciones entre personas naturales, que es el contrato de trabajo por tiempo determinado a tenor del artículo 72, representa no solo una limitante para el reconocimiento de un vínculo de trabajo estable, sino que impacta negativamente en el cómputo de los referidos tiempos para acceder al beneficio de la maternidad con cobro de prestación económica. A este respecto, el legislador pudo ser más exquisito en el tratamiento de los preceptos 73 y 74, los cuales fijan el carácter de mínimos en cuanto a la formalización de estas relaciones (cláusulas contractuales y derechos a garantizar por el empleador, respectivamente), pero no precisan la situación femenina en relación con la maternidad. 
Teniendo en cuenta lo planteado -desde el análisis de la perspectiva de la equidad de género-, se vulnera, sin dudas, el principio constitucional de igualdad y no discriminación que debe regir para toda mujer trabajadora en estado de gestación, con independencia del sector donde se encuentre contratada. Específicamente, se transgreden los artículos 42, 44 y 68 de la Constitución de la República de Cuba de 2019, los cuales plantean:

Artículo 42. Todas las personas son iguales ante la ley, reciben la misma protección y trato de las autoridades y gozan de los mismos derechos, libertades y oportunidades, sin ninguna discriminación por razones de sexo, género, orientación sexual, identidad de género, edad, origen étnico, color de la piel, creencia religiosa, discapacidad, origen nacional o territorial, o cualquier otra condición o circunstancia personal que implique distinción lesiva a la dignidad humana.

Artículo 44. El Estado crea las condiciones para garantizar la igualdad.

Artículo 68. La persona que trabaja tiene derecho a la seguridad social. El Estado, mediante el sistema de seguridad social, le garantiza la protección adecuada cuando se encuentre impedida de laborar por su edad, maternidad, paternidad, invalidez o enfermedad.

Se está en presencia de una normativa discriminatoria que coloca en una posición de desventaja a la mujer que tiene como proyecto de vida el ejercicio de un trabajo digno con garantías formales y materiales para emprender la maternidad.

Debe tenerse en cuenta, además, que es este un sector (el de TCP) que en la Cuba de hoy gana cada vez mayor participación social y plantea al Estado el reto de cumplir con sus fines esenciales constitucionalmente establecidos, entre ellos, el de garantizar la igualdad efectiva en el disfrute y ejercicio de los derechos, y en el cumplimiento de los deberes consagrados en la Constitución y las leyes (artículo 13: Fines esenciales del Estado, inciso g); así como el artículo 41 que afirma: "El Estado cubano reconoce y garantiza a la persona el goce y el ejercicio irrenunciable, imprescriptible, indivisible, universal e interdependiente de los derechos humanos, en correspondencia con los principios de progresividad, igualdad y no discriminación. Su respeto y garantía es de obligatorio cumplimiento para todos".

Se considera además que el hecho de haberse aprobado en el año 2016 una nueva normativa para la protección de la maternidad de la trabajadora en el sector estatal de la economía en Cuba (el Decreto-Ley 339), debió suponer el análisis y perfeccionamiento de dicha protección para el resto de los sectores económicos presentes en el país por novedosos que fueran.

Asimismo, se coincide con Silva y Pérez (2019) en que ofrecer garantías a la mujer en el marco de las relaciones laborales para una adecuada maternidad que facilite su atención médica, el descanso pre y postnatal y el cuidado de los hijos menores es ineludible, teniendo en cuenta que la maternidad ha constituido desde el propio surgimiento de la especie humana, un medio de supervivencia no solo para el sostenimiento de la familia y la satisfacción de las necesidades vitales, sino para impulsar el progreso social y por ende el desarrollo de la humanidad. 


\section{Conclusiones}

La maternidad ha sido concebida como una construcción sociocultural asociada a la subjetividad femenina, cuyo tratamiento jurídico se vincula con el derecho de toda mujer a su ejercicio, siempre que tenga las condiciones requeridas para ello y con independencia de su estatus laboral. Sin embargo, aun cuando su protección se considera como un derecho fundamental, consagrado en tratados universales de derechos humanos, reviste implicaciones particulares para las relaciones laborales que interesan tanto a hombres como a mujeres.

Desde el punto de vista teórico, se evidencia un abordaje epistemológico de la categoría maternidad en sus aristas biológica, sociocultural y jurídica. En esta última, se imbrican el tratamiento desde ramas específicas tales como el Derecho Constitucional y el Derecho del Trabajo y de Seguridad Social, con el desarrollo de áreas de estudios más transversales como la teoría feminista, el enfoque de género y el lenguaje inclusivo -visto más allá de lo meramente lingüístico.

Se reconoce la necesidad de deslindar los estudios jurídicos feministas del análisis de la relación géneros-sexualidades. Con respecto a este último enfoque, se requiere distinguir conceptualmente las categorías igualdad de género, equidad de género e identidad de género, teniendo en cuenta que la igualdad tiene que ver con los mismos derechos para todos los géneros o con medidas políticas compensatorias o correctivas que tiendan a la igualdad y la no discriminación, lo que implica no solo la redistribución económica sino también la de poder. Por su parte, las identidades de género se enfocan desde la sexualidad humana y se refieren más bien a los estereotipos y roles que asignan las sociedades patriarcales a cada género. Es por ello que su abordaje transversaliza tanto a los estudios de género como a la teoría feminista.

En cuanto a la normatividad, resulta trascendente la creación y adopción de mecanismos internacionales en el seno de las Naciones Unidas que atienden la protección y promoción de este derecho humano; que a su vez se expresa en los ordenamientos jurídicos internos a través de su constitucionalización, o en normas especiales como las laborales y de seguridad social.

Sobre la base de integrar las diferentes perspectivas de análisis, se entiende el derecho a la maternidad de la trabajadora como aquel que le asiste a la embarazada que ocupa un puesto de trabajo de recibir a través del Sistema de Seguridad Social prestaciones en servicios, en especies y monetarias para asegurar su estatus, desde la concepción hasta los meses iniciales de alumbramiento, de manera tal que se preserven su salud y la del recién nacido, y que resulte habilitada para combinar satisfactoriamente sus roles reproductivo y productivo una vez reincorporada a su plaza habitual, a la vez que se preserven las garantías para el ejercicio del resto de sus derechos laborales.

El estudio legislativo realizado para el contexto nacional cubano evidencia la vulneración del principio constitucional de igualdad y no discriminación, regulado en la vigente Constitución de la República de Cuba de 2019, pues la comparación jurídica desarrollada arroja como resultado la transgresión de los artículos constitucionales 13 , $41,42,44$ y 68, respectivamente. En tal sentido, si bien el derecho de la trabajadora a la seguridad social por causa de la maternidad consta de amparo constitucional en dicho artículo 68, ello representa solo una garantía formal y no material, ante la existencia de 
un desequilibrio entre las prestaciones que se ofrecen para las contratadas en el sector estatal de la economía y las contratadas en el sector cuentapropista.

Específicamente, las mencionadas trabajadoras del sector no estatal cuentapropista son víctimas de una normativa discriminatoria que, en solo siete artículos, regula las prestaciones por maternidad, sin tener en cuenta derechos conexos tales como: de reincorporación a la plaza de trabajo; de percibir la prestación social que se otorga a la madre, padre o familiar a quien se encargue el cuidado del menor al vencimiento de la licencia postnatal y hasta que este arribe a su primer año de vida; a la simultaneidad del cobro de la prestación social con el salario; a la disponibilidad de tiempo para la atención estomatológica; y a la suspensión de la relación laboral con carácter obligatorio para garantizar su descanso ante la proximidad del parto, así como para su recuperación posterior al nacimiento del menor.

En tanto, en el sector de las CNoA la normativa en vigor carece de contenido propio que refrende las prestaciones económicas y sociales, y reenvía a la cooperativista embarazada al disfrute de las prestaciones del régimen jurídico estatal.

En el presente contexto de actualización del modelo económico y social cubano de desarrollo socialista $y$, por ende, de perfeccionamiento del ordenamiento jurídico, el Estado tiene el reto y debe, conforme a la vigente Constitución, reconocer los mismos derechos para las trabajadoras sin importar el sector al que se afilien, ya que el derecho a la maternidad como derecho conquistado en Cuba hace más de cincuenta años en el sector estatal, debe hacerse extensivo para el resto de las formas de gestión económica, por el bienestar de la mujer y por una sociedad cada vez más justa y equitativa.

\section{Referencias}

Addati, L., Cassirer, N., y Gilchrist, K., 2014. Maternity and paternity at work: Law and practice across the world [en línea]. Informe. Ginebra: Organización Internacional del Trabajo. Disponible en: https://www.ilo.org/wcmsp5/groups/public/--dgreports/---dcomm/---publ/documents/publication/wcsm_242615.pdf [Con acceso el 28 de enero de 2021].

Arendell, T., 2000. Conceiving and investigating motherhood: The decade's scholarship. Journal of Marriage and Family [en línea], 1192-1207. Disponible en: https://doi.org/10.1111/j.1741-3737.2000.01192.x [Con acceso el 28 de enero de 2021].

Berrocal, J.C., y Reales, R.J., 2016. La licencia de maternidad en el derecho comparado. Justicia Juris, [en línea], 12(1), 100-106. Disponible en: https://doi.org/10.15665/rj.v12i1.891 [Con acceso el 28 de enero de 2021].

Camargo, J., 1999. Género e Investigación Social. Curso de Formación en Género. Módulo 2 [en línea]. $1^{a}$ ed. Instituto de la Mujer de la Universidad de Panamá/UNICEF/Sibauste. Disponible en: http://biblioteca.udelas.ac.pa/cgibin/koha/opac-imageviewer.pl?biblionumber $=9065$ [Con acceso el 28 de enero de 2021].

Contreras, P., 2018. Maternidad encarcelada: análisis feminista de las consecuencias personales, familiares y sociales en mujeres privadas de libertad. Revista Temas 
Sociológicos [en línea], n.ํ22, 209-232. Disponible en: https://doi.org/10.29344/07196458.22.1683 [Con acceso el 28 de enero de 2021].

Duarte, R.J., 2004. Evolución del concepto de maternidad y de las acciones para impugnarla. Capítulo 1: La maternidad en el Código Civil chileno [en línea]. Memoria para optar por el grado de Licenciada en Ciencias Jurídicas y Sociales. Universidad Austral de Chile, Facultad de Ciencias Jurídicas y Sociales, Escuela de Derecho. Disponible en: http://cybertesis.uach.cl/tesis/uach/2004/fjd812e/pdf/fjd812eTH.2.pdf [Con acceso el 28 de enero de 2021].

Dujarric, G., y Vázquez, M., 2015. Identidades sociales de sujetos con alto capital económico. Tesis de maestría. Facultad de Psicología, Universidad de La Habana.

Echeverría, D., y Lara, T., 2012. Cambios recientes: ¿oportunidad para las mujeres? En: A. Pavel y O.E. Pérez, eds., Miradas a la economía cubana: el proceso de actualización, La Habana: Caminos, 126-137.

Figueroa, G., 1995. Persona, pareja y familia. Santiago de Chile: Editorial Jurídica de Chile.

Gamboa, C., y Valdés, S., 2008. Derechos de la maternidad: Estudio teórico conceptual, de iniciativas presentadas, y de derecho comparado [en línea]. Mayo. Ciudad de México: Centro de Documentación, Información y Análisis Servicios de Investigación y Análisis Política Interior. Disponible en: http://www.diputados.gob.mx/sedia/sia/spi/SPI-ISS-12-08.pdf [Con acceso el 28 de enero de 2021].

González, J.M., 2015. Autonomía reproductiva y Derecho: Un análisis de los marcos jurídicos internacional, europeo y español, desde la teoría jurídica feminista [en línea]. Tesis Doctoral, Universitat Autònoma de Barcelona, Departament de Ciència Política i de Dret Públic, 1-379. Disponible en: https://www.tdx.cat/handle/10803/309284\#page=1 [Con acceso el 28 de enero de 2021].

Imaz, E., 2010. Convertirse en madre: Etnografía del tiempo de gestación. Valencia/Madrid: Universidad de Valencia/Instituto de la Mujer/Cátedra. Disponible en: https://my.b-ok.as/book/5682004/2803f0 [Con acceso el 28 de enero de 2021].

Kurczyn, P., 2004. Acoso sexual y discriminación por maternidad en el trabajo. Instituto de investigaciones jurídicas de la Universidad Nacional Autónoma de México. Disponible en: https://www.marcialpons.es/libros/acoso-sexual-y-discriminacionpor-maternidad-en-el-trabajo/9789703215195/ [Con acceso el 28 de enero de 2021].

Mander, R., et al., 2014. The politics of maternity. The practising midwife [en línea], 17(2), 21-3. Disponible en: https://www.ncbi.nlm.nih.gov/pubmed/24600828 [Con acceso el 28 de enero de 2021].

Marrades, A., 2002. Luces y sombras del derecho a la maternidad: Análisis jurídico de su reconocimiento. Universitat de València.

Maurizio, R., 2010. Enfoque de género en las instituciones laborales y las políticas del mercado de trabajo en América Latina (LC/L.3230-P) [en línea]. División de Desarrollo Económico de la Comisión Económica para América Latina y el Caribe (CEPAL) 
de Naciones Unidas. Disponible en:

https://www.cepal.org/es/publicaciones/5333-enfoque-genero-institucioneslaborales-politicas-mercado-trabajo-america-latina [Con acceso el 28 de enero de 2021].

Miranda, B., y Peña, V., 2001. Relaciones de género con equidad: Guía conceptual y metodológica [en línea]. San Salvador: IICA-Holanda/LADERAS. Disponible en: http://repiica.iica.int/docs/B1178e/B1178e.pdf [Con acceso el 28 de enero de 2021].

Molina, M.E., 2006. Transformaciones histórico-culturales del concepto de maternidad y sus repercusiones en la identidad de la mujer. Psykhe [en línea], 15(2), 93-103. Disponible en: https://doi.org/10.4067/S0718-22282006000200009 [Con acceso el 28 de enero de 2021].

Moncó, B., 2009. Maternidad ritualizada: Un análisis desde la antropología de género. AIBR, Revista de Antropología Iberoamericana [en línea], 4(3), 357-384. Disponible en: https://www.redalyc.org/pdf/623/62312914005.pdf [Con acceso el 28 de enero de 2021].

Odriozola, S., y Colina, H., 2018. El sistema de pensiones de la Seguridad Social en Cuba: retos actuales [en línea]. Disponible en:

http://www.researchgate.net/publication/323918198 [Con acceso el 28 de enero de 2021].

Ossorio, M., 2004. Diccionario de ciencias jurídicas, políticas y sociales. Buenos Aires: Heliasta.

Partido Comunista de Cuba (PCC), 2017. Lineamientos de la Política Económica y Social del Partido y la Revolución para el período 2016-2021. Tabloides I y II. UEB Gráfica, Empresa de periódicos de Cuba.

Pérez, L., 2011. “Algunas consideraciones a debate sobre la ciencia jurídica y sus métodos". Revista Cubana de Derecho [en línea], 23-49. Disponible en: https://vlex.com/source/revista-cubana-derecho-2615/issue nbr/\%2338 [Con acceso el 28 de enero de 2021].

Ramírez-Ramírez, V., 2013. Una aproximación sociocultural a la no-maternidad voluntaria [en línea]. Tesis de maestría en Comunicación de la Ciencia y la Cultura. Tlaquepaque: ITESO. Disponible en: http://hdl.handle.net/11117/2517 [Con acceso el 28 de enero de 2021].

Rodríguez, Y., 2014. La contratación laboral en el sector no estatal en Cuba. Actualidad y perspectivas. Relaciones laborales: Revista crítica de teoría y práctica, nº 6, 105-118.

Rodríguez, Y., y Páez, M., 2016. Desarrollo social y política de empleo a propósito del Código de Trabajo cubano. Estudios del Desarrollo Social: Cuba y América Latina [en línea], 4(3), 1-14. Disponible en:

http://scielo.sld.cu/scielo.php?script=sci arttext\&pid=S2308-01322016000300001 [Con acceso el 28 de enero de 2021].

Silva, J.-L., y Pérez, A., 2017. Enfoque de género en la evolución del ordenamiento jurídico cubano y su manifestación en el Derecho Penal actual. Estudios del Desarrollo Social: Cuba y América Latina [en línea], 5(2), 1-11. Disponible en: 
http://scielo.sld.cu/scielo.php?script=sci arttext\&pid=S2308-01322017000200007 [Con acceso el 28 de enero de 2021].

Silva, J.L., y Pérez, A., 2019. El derecho de la mujer al trabajo y a la maternidad en Cuba. Revista de Ciencias Médicas de Pinar del Río [en línea], 23(1), 147-158.

Disponible en:

http://revcmpinar.sld.cu/index.php/publicaciones/article/view/3718- [Con acceso el 28 de enero de 2021].

Trujillo, I., y Hernández, C.N., 2008. La multidimensionalidad de la categoría género y del feminismo. En: C.N. Hernández, ed., Género, selección de lecturas. Compilación. La Habana: Caminos.

Valdebenito, E., 2002. Género y Desarrollo (algunas reflexiones y un glosario práctico para facilitar el trabajo a nivel local). Programa DelNet - Gender Equality - Centro Internacional de Formación de la OIT.

Walker, C., 1995. "Conceptualizing motherhood in twenty century South Africa", Journal of Southern African Studies [en línea], 21(3), 417-437. Disponible en: https://doi.org/10.1080/03057079508708455 [Con acceso el 28 de enero de 2021].

\section{Normativa}

Alianza Cooperativa Internacional para las Américas, 2009. Ley Marco para las Cooperativas de América Latina [en línea]. 1aed. San José: Alianza Cooperativa Internacional para las Américas. Disponible en:

http://www.aciamericas.coop/IMG/pdf/LeyMarcoAL.pdf [Con acceso el 28 de enero de 2021].

Constitución de la República de Cuba, 2019. Gaceta Oficial de la República de Cuba [en línea] Extraordinaria (GOC-2019-406-EX5) de 10 de abril de 2019. Disponible en: https://www.cubahora.cu/uploads/documento/2019/04/11/goc-2019-ex5.pdf [Con acceso el 28 de enero de 2021].

Declaración Universal de los Derechos Humanos de 1948, 2016. En: C.E. Pino, Selección de Instrumentos Jurídicos Internacionales (Tomo 3). La Habana: Editorial Universitaria Félix Varela.

Decreto Ley N.․ 339 de 8 de diciembre de 2016. De la maternidad de la trabajadora. Gaceta Oficial de la República de Cuba [en línea], n. 7, de 10 de febrero de 2017. Disponible en: http://juriscuba.com/legislacion-2/decretos-leyes/decreto-ley-no339/ [Con acceso el 28 de enero de 2021].

Decreto-Ley N ․ 306 de 2012, Del Régimen especial de Seguridad Social de los socios de las Cooperativas no Agropecuarias. Gaceta Oficial de la República de Cuba [en línea], n. ${ }^{\circ}$ 053, Extraordinaria, de 11 de diciembre. Disponible en:

https://www.gacetaoficial.gob.cu/sites/default/files/go x 053 2012.pdf [Con acceso el 28 de enero de 2021].

Decreto-Ley N.․ 326 de 12 de junio de 2014. Reglamento del Código de Trabajo. Gaceta Oficial de la República de Cuba [en línea], n.ํ29 29, Extraordinaria, de 17 de junio. Disponible en: https://www.fao.org/faolex/results/details/en/?details=LEXFAOC134816- [Con acceso el 28 de enero de 2021]. 
Decreto-Ley-N.․ 278 de 6 de septiembre de 2011. Del régimen especial de seguridad social para los trabajadores por cuenta propia. Gaceta Oficial de la República de Cuba [en línea], n.o 028, Extraordinaria, de 6 de septiembre de 2011. Disponible en: https://oig.cepal.org/sites/default/files/2010 dl278 cub.pdf [Con acceso el 28 de enero de 2021].

Ley Fundamental de 7 de febrero de 1959 [en línea]. Disponible en:

https://archivos.juridicas.unam.mx/www/bjv/libros/6/2525/38.pdf [Con acceso el 28 de enero de 2021].

Ley N.․ 105/2008 de Seguridad Social de 22 de enero de 2008. Gaceta Oficial de la República de Cuba [en línea], n.o 004, Extraordinaria, de 22 de enero. Disponible en: www.ilo.org/dyn/natlex/docs/ELECTRONIC/80586/87091/F744296863/CUB80586. pdf [Con acceso el 28 de enero de 2021].

Ley N.ำ 116 del 20 de diciembre de 2013. Código de Trabajo de la República de Cuba. Gaceta Oficial de la República de Cuba [en línea], n.ํㅜㄹ, Extraordinaria, de 17 de junio de 2014. Disponible en: https://oig.cepal.org/sites/default/files/2013 ley116 cub.pdf [Con acceso el 28 de enero de 2021].

Pacto Internacional de Derechos Económicos, Sociales y Culturales de 1948. Adoptado y abierto a la firma, ratificación y adhesión por la Asamblea General de Naciones Unidas en su resolución 2200 A (XXI), de 16 de diciembre de 1966. Entrada en vigor: 3 de enero de 1976, de conformidad con el artículo 27 [en línea]. Disponible en:

https://www.ohchr.org/sp/professionalinterest/pages/cescr.aspx [Con acceso el 28 de enero de 2021].

Resolución N.․ 33. Reglamento para el ejercicio del Trabajo por Cuenta Propia. Gaceta Oficial de la República de Cuba [en línea], n.ํ29, Extraordinaria, de 7 de septiembre de 2011. Disponible en:

https://www.gacetaoficial.gob.cu/sites/default/files/go x 029 2011.pdf [Con acceso el 28 de enero de 2021]. 